\title{
Collagen type III glomerulopathy
}

INSERM

\section{Source}

INSERM. (1999). Orphanet: an online rare disease and orphan drug data base. Collagen type III glomerulopathy. ORPHA:84087

Collagen type III glomerulopathy is a rare glomerular disease characterized by abnormal accumulation of type III collagen within the mesangium and subendothelial space of the glomerulus. Clinically it usually manifests with proteinuria (often in the nephrotic range), microscopic hematuria, peripheral edema and/or hypertension. In some cases, progression to end-stage renal failure is observed. 